\title{
Retroviral expression of human arginine decarboxylase reduces oxidative stress injury in mouse cortical astrocytes
}

\author{
Samin Hong ${ }^{1}$, Mi Ran Son², Kyungeun Yun², Won Taek Lee ${ }^{2}$, Kyung Ah Park² and Jong Eun Lee 2* $^{*}$
}

\begin{abstract}
Background: In physiologic and pathologic conditions of the central nervous system (CNS), astrocytes are a double-edged sword. They not only support neuronal homeostasis but also contribute to increases in neuronal demise. A large body of experimental evidence has shown that impaired astrocytes play crucial roles in the pathologic process of cerebral ischemia; therefore, astrocytes may represent a breakthrough target for neuroprotective therapeutic strategies. Agmatine, an endogenous polyamine catalyzed from L-arginine by arginine decarboxylase (ADC), is a neuromodulator and it protects neurons/glia against various injuries.
\end{abstract}

Results: In this investigation, agmatine-producing mouse cortical astrocytes were developed through transduction of the human ADC gene. Cells were exposed to oxygen-glucose deprivation (OGD) and restored to a normoxic glucose-supplied condition. Intracellular levels of agmatine were measured by high performance liquid chromatography. Cell viability was evaluated by Hoechest/propidium iodide nuclear staining and lactate dehydrogenase assay. Expression of inducible nitric oxide synthase (iNOS) and matrix metalloproteinase $s$ (MMPs) were assessed by a reverse transcription polymerase chain reaction, Western immunoblots, and immunofluorescence. We confirmed that ADC gene-expressed astrocytes produce a great amount of agmatine. These cells were highly resistant to not only OGD but also restoration, which mimicked ischemia-reperfusion injury in vivo. The neuroprotective effects of ADC seemed to be related to its ability to attenuate expression of iNOS and MMPs.

Conclusion: Our findings imply that astrocytes can be reinforced against oxidative stress by endogenous agmatine production through ADC gene transduction. The results of this study provide new insights that may lead to novel therapeutic approaches to reduce cerebral ischemic injuries.

Keywords: Agmatine, Arginine decarboxylase, Astrocyte, Neuroprotection, Oxidative stress

\section{Background}

Astrocytes comprise the structural architecture of the brain and support neurons to maintain homeostasis [1,2]. Physiologically, they stabilize the extracellular environment of neurons: they control ion/water distribution, regulate neurotransmitter recycling, release growth factors, and scavenge reactive oxygen species (ROS). Under pathologic conditions, when noxious stress exceeds limitations, astrocytes work in the opposite direction [1,2]. Water accumulation induces brain edema, failure of neurotransmitter

\footnotetext{
* Correspondence: jelee@yuhs.ac

${ }^{2}$ Brain Korea 21 Project for Medical Science, and Brain Research Institute, Department of Anatomy, Yonsei University College of Medicine, 50 Yonsei-ro, Seodaemun-gu, Seoul 120-752, Republic of Korea

Full list of author information is available at the end of the article
}

control, which causes glutamate excitotoxicity; and releases ROS/neurotoxic factors that contribute to further neuronal damage. In cerebral injuries, astrocytes are the main culprit of neurodegeneration and scar formation [2,3]. Meanwhile, they also contribute to neurite outgrowth and neurogenesis [4]. Astrocytes have recently garnered attention as a breakthrough target in development of new therapeutic strategies for patients suffering from neuronal damage [2].

Agmatine, an endogenous polyamine derived from L-arginine by arginine decarboxylase (ADC), is naturally found in the mammalian central nervous system (CNS) and acts as a multifunctional neuromodulator [5-7]. It is packed into synaptic vesicles and released from synaptosomes by neuronal depolarization [8,9]. Agmatine can stimulate $\alpha_{2}$-adrenergic and imidazoline receptors $[10,11]$, 
block the N-methyl-D-aspartic acid (NMDA) receptor and voltage-gated calcium channel $[12,13]$, and inhibit inducible/neuronal nitric oxide synthases (iNOS/nNOS) $[14,15]$. Through these kinds of intracellular signaling, agmatine shows various antineurotoxic, anticonvulsant, antipsychotic, antidepressant, anxiolytic, and antinociceptive neuroprotective effects $[7,16]$. Regarding ischemic insults, exogenous agmatine significantly reduces the infarct size and brain edema caused by ischemiareperfusion injury in rodents [17-20]. Agmatine also rescues glial cells, as well as cortical neurons, from oxidative stress in vitro and in vivo $[17,21,22]$.

In this study, a recombinant retroviral vector containing the human ADC (hADC) gene was introduced into mouse cortical astrocytes to maximize the astrocyte-protective effect of agmatine. Cells overexpressing hADC show increased production of agmatine and greater resistance against oxidative stress [23-25]. Here, we transduced primary cultured cortical astrocytes with hADC-expressing retroviral vector and assessed whether it induces synthesis of endogenous agmatine and attenuates oxidative stress injuries.

\section{Methods \\ Cell culture}

Primary cortical astrocyte cultures were prepared from postnatal 1-3 days old Crl:CD1 mouse pups (Samtako, Osan, Korea) [21,26]. Our protocol was approved by the Institutional Animal Care and Use Committee of Yonsei University College of Medicine and all animals were treated in accordance with their guidelines. Animals were etherized and decapitated on ice-cold ethanol. Cortical hemispheres were dissected free of the skull and meninges, and then treated with $0.09 \%$ trypsin for $20 \mathrm{~min}$ at $37^{\circ} \mathrm{C}$. The cells were mechanically dissociated into single cells and collected as a suspension. The cells were grown in minimum essential medium (MEM; Life Technologies, Grand Island, NY) containing $10 \%$ fetal bovine serum (FBS) and 10\% equine serum (Thermo Fisher Scientific, Waltham, MA). The cultures were incubated at $37^{\circ} \mathrm{C}$ in a $5 \% \mathrm{CO}_{2}$ incubator and the culture media was replaced every 3 days. One week after the first seeding, the other cells including microglia were removed by vigorous shaking. The highly-purified astrocytes (passage 3), at least 3 weeks after the first seeding, were used for experiments at about $80 \%$ confluence (Additional file 1).

\section{Construction and infection of recombinant retroviral vector containing the $\mathrm{hADC}$ gene}

A recombinant retroviral vector containing the hADC gene was constructed as described previously (Figure 1) [23-25]. Briefly, the full-length cDNA of hADC (GenBank accession no. AY325129) was amplified by a polymerase chain reaction (PCR) and ligated to the retroviral expression vector pLXSN (Clontech Laboratories, Mountain View, CA) that also contained a neomycin resistance gene. They were then amplified in E.coli DH5a and identified by restriction analysis. The hADC-expressing $\mathrm{pLXSN}$ vector was transfected into the retroviral packaging cell line PT67 using Lipofectamine 2000 (Sigma-Aldrich, St. Louis, $\mathrm{MO})$. A stable clone selection was carried out by adding G418 (200 $\mu \mathrm{g} / \mathrm{mL}$; Sigma-Aldrich) to the culture medium of Dulbecco's modified Eagle's medium (DMEM, Life Technologies) supplemented with 10\% FBS. High-titer clones were selected, and virus-containing supernatant was filtered through a $0.45-\mathrm{mm}$ polysulfonic filter. Primary cultured mouse cortical astrocytes were infected with hADC pLXSN. The cells were incubated with the virus-containing media for $24 \mathrm{hrs}$ and then maintained in normal culture medium for a week before being used for the experiments.

\section{Oxygen-glucose deprivation and restoration}

For oxygen-glucose deprivation (OGD), cultures were transferred to a closed anaerobic chamber (Forma Scientific Co., Seoul, Korea) in which the oxygen level (less than $\left.0.1 \% \mathrm{O}_{2}\right)$ and temperature $\left(37^{\circ} \mathrm{C}\right)$ were controlled automatically $[21,27]$. After being washed three times with deoxygenated, glucose-free balanced salt solution $\left(\mathrm{BSS}_{0}\right)$ at $\mathrm{pH} 7.4$, cells were kept in the anaerobic chamber for 4 hours. Cultures were then restored with glucose at a concentration of $5.5 \mathrm{mM}\left(\mathrm{BSS}_{5.5}\right)$ and recovered to normoxic conditions $\left(37^{\circ} \mathrm{C}, 5 \% \mathrm{CO}_{2}\right)$ for up to 10 hours.

\section{High performance liquid chromatography analysis}

The concentration of agmatine was measured by high performance liquid chromatography (HPLC) [23,24]. Harvested cells were homogenized in phosphate buffer containing $10 \%$ trichloroacetic acid and centrifuged at $12,000 \mathrm{rpm}$ for $10 \mathrm{~min}$. The collected supernatant was derivatized with o-phthalaldehyde and loaded onto the HPLC column $(5 \mathrm{~mm})$ connected with a fluorescence detector. Recovery of agmatine was calculated from an added external standard. The content of L-Arginine and putrescine was also measured using same method.

\section{Hoechst and propidium iodide nuclear staining}

Cell death was characterized by double nuclear staining with Hoechst 33258 and propidium iodide (PI) [23,24]. Cells were stained with Hoechst 33258 dye $(5 \mu \mathrm{g} / \mathrm{mL}$; Sigma-Aldrich) for $30 \mathrm{~min}$ at $37^{\circ} \mathrm{C}$ and consecutively stained with PI $(5 \mu \mathrm{g} / \mathrm{mL}$; Sigma-Aldrich) just before observing it with a fluorescence microscope. Living cells showed Hoechst-positive blue fluorescence and nonviable cells had PI-positive red fluorescence. 


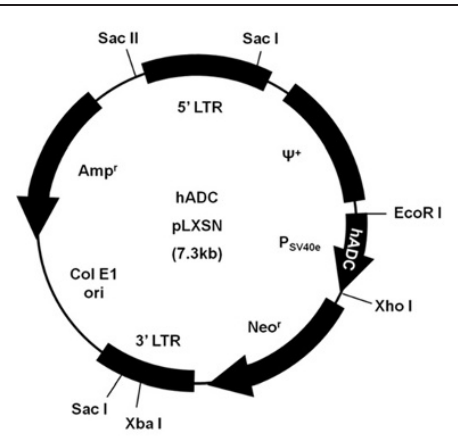

A

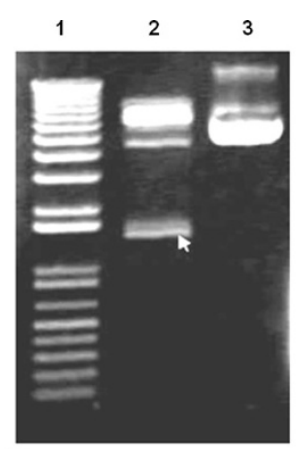

B

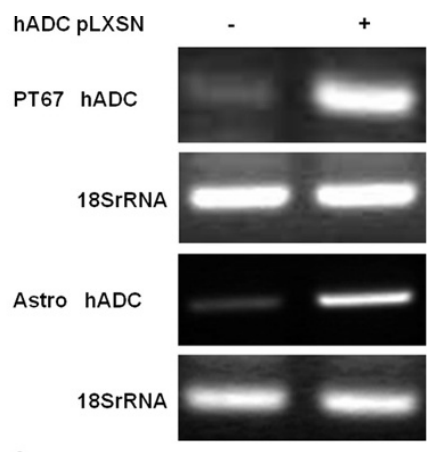

C

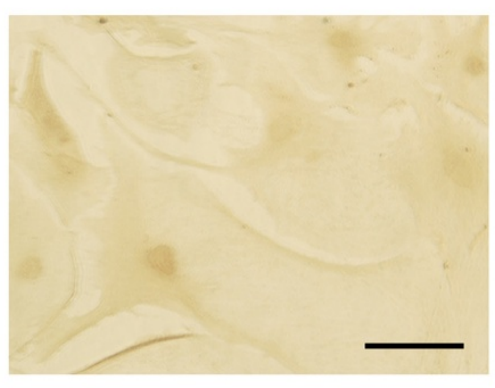

hADC PLXSN

D

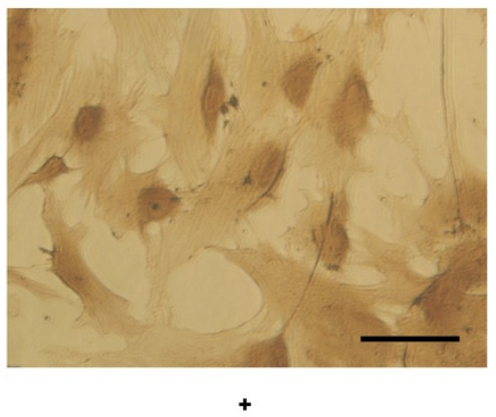

Figure 1 Construction and infection of recombinant retroviral vector containing the human arginine decarboxylase (hADC) gene.

(A) hADC pLXSN vector map: hADC pLXSN includes the Col E1 origin of replication and E.coli Amp ${ }^{r}$ gene for propagation and antibiotic selection The $5^{\prime}$ viral LTR in this vector contains promoter/enhancer sequences that control expression of the gene of interest in the multiple cloning site. The SV40 early promoter $\left(\mathrm{PSV}_{4} \mathrm{e}\right.$ ) controls expression of the neomycin resistance gene (Neo'), which allows antibiotic selection in eukaryotic cells. (B) Genetic confirmation by restriction analysis: Lane 1, size marker; Lane 2, restriction enzyme digestion using EcoRI and Xhol; Lane 3, control hADC pLXSN. (C) RNA levels of hADC were verified by RT-PCR in PT67 cells and mouse cortical astrocytes (Astro) after hADC pLXSN infection. (D) Expression of hADC was validated by immunocytochemistry in hADC pLXSN-infected astrocytes. Scale bar $=50 \mu \mathrm{m}$.

\section{Lactate dehydrogenase activity}

Cell viability was quantified by measuring the amounts of lactate dehydrogenase $(\mathrm{LDH})$ released from injured cells into the medium [27-30]. LDH released (\% cytotoxicity) was calculated by dividing the value at the experimental time point by the maximum value $\times 100$. Maximum LDH release values were obtained after freezing each culture at $-70^{\circ} \mathrm{C}$ overnight and then rapidly thawing them, thus inducing nearly complete cell damage.

\section{Reverse transcription polymerase chain reaction}

Gene expression was assessed by reverse transcription PCR (RT-PCR) [23,24]. Total RNA was extracted from cells with Trizol (Life Technologies) and quantified by measuring the absorbance at $260 \mathrm{~nm}$. cDNA synthesis from mRNA and normalization of the samples were carried out by RT-PCR. PCR amplification of iNOS was performed at $94^{\circ} \mathrm{C}$ for $30 \mathrm{~s}, 57.5^{\circ} \mathrm{C}$ for $30 \mathrm{~s}$, and $72^{\circ} \mathrm{C}$ for $30 \mathrm{~s}$ for 30 cycles. Amplification of MMP-2 was performed at $94^{\circ} \mathrm{C}$ for $30 \mathrm{~s}, 53^{\circ} \mathrm{C}$ for $30 \mathrm{~s}$, and $72^{\circ} \mathrm{C}$ for $30 \mathrm{~s}$ for 35 cycles. Amplification for MMP-9 was performed at $94^{\circ} \mathrm{C}$ for $30 \mathrm{~s}, 59^{\circ} \mathrm{C}$ for $30 \mathrm{~s}$, and $72^{\circ} \mathrm{C}$ for $30 \mathrm{~s}$ for 30 cycles. Specific primer sequences used are as follows: iNOS, sense
5'-TTT GAT GTG CTG CCT CTG GT-3' and antisense 5'-CAT TCT GCT TCT GGA AAC TAA GG-3'; MMP-2, sense 5'-GAG TTG GCA GTG CAA TAC CT-3' and antisense, 5'-GCC GTC CTT CTC AAA GTT GT-3'; MMP-9, sense 5'-TTA CCA GCG CCA GCC GAC TTT TG-3' and antisense 5'-CGT CGT CGT CGA AAT GGG CAT C-3'; Glyceraldehyde 3-phosphate dehydrogenase (GAPDH), sense 5'-ATG TCG TGG AGT CTA CTG GT-3' and antisense 5'-TGG CAT GGA CTG TGG TG-3'. PCR products were separated by electrophoresis in a $1.5 \%$ agarose gel stained with ethidium bromide.

\section{Western immunoblots}

Protein levels were determined by Western immunoblots [23,24,31]. Protein was extracted from whole cell lysates, and their concentration was calculated with the BCA protein assay (Thermo Fisher Scientific). Equal amounts of protein $(40 \mu \mathrm{g})$ from each sample were resolved on a $10 \%$ sodium dodecyl sulfate-polyacrylamide gel. The separated proteins were then electrotransferred onto Immobilon-NC membranes (Millipore, Billerica, MA) and incubated overnight with primary antibodies against iNOS (1:1000 dilution), MMP-2 (1:2000 dilution), MMP-9 
(1:2000 dilution), or $\beta$-actin (1:2000 dilution). The primary antibody against iNOS was purchased from Millipore (Billerica, MA) and the others were obtained from Santa Cruz Biotechnology (Dallas, TX). Immunoreactive bands were detected with horseradish peroxidase-conjugated secondary antibody and visualized using an enhanced chemiluminescent protein detection kit (Thermo Fisher Scientific).

\section{Immunofluorescence staining}

Protein expression was also confirmed by immunofluorescence $[23,31,32]$. Cells were fixed with $90 \%$ ethanol for $30 \mathrm{~min}$ on ice, and then treated with $1.6 \%$ hydrogen peroxide and $0.025 \%$ triton. They were reacted with specific antibodies (1:500 dilution) for iNOS (Millipore), MMP-2 (Santa Cruz Biotechnology), MMP-9 (Santa Cruz Biotechnology), and glial fibrillary acidic protein (GFAP; Abcam, Cambridge, MA). Subsequently, the cells were exposed to the corresponding fluorescent secondary antibodies (Life Technologies) and their nuclei were counterstained with 4;6-diamidino-2-phenylindole (DAPI; Sigma-Aldrich). Finally, four random fields were imaged under a fluorescence microscope. Immunoreactive cells with fluorescence were manually counted at 200× magnification.

\section{Statistical analysis}

Data are presented at the mean of \pm SD of at least three different experiments performed from separate cell preparations, with at least triplicate determination performed for each experiment. Kruskal-Wallis test and Mann-Whitney test were used in order to examine statistical significance (MedCalc Statistical Software version 12.7.8.; MedCalc Software bvba, Ostend, Belgium). P-values less than 0.05 were considered statistically significant.

\section{Results}

Transduction of mouse cortical astrocytes with recombinant retroviral vector containing the human arginine decarboxylase (hADC) gene

The vector map of hADC pLXSN is shown in Figure 1A. It includes the Col E1 origin of replication and E.coli $A m{ }^{r}$ gene for propagation and antibiotic selection. The 5 ' viral LTR contains promoter/enhancer sequences that control expression of the gene of interest in the multiple cloning site. The SV40 early promoter $\left(\mathrm{PSV}_{4} \mathrm{e}_{\mathrm{e}}\right.$ ) controls expression of the neomycin resistance gene $\left(\mathrm{Neo}^{\mathrm{r}}\right)$, which allows for antibiotic selection in eukaryotic cells. $\mathrm{PSV} \mathrm{e}_{\mathrm{e}}$ was genetically confirmed by restriction analysis (Figure 1B). In astrocytes, as well as PT67 cells, infection of the hADC pLXSN vector effectively induced hADC transcription (Figure 1C). Expression of hADC was validated by immunocytochemistry in hADC pLXSN-infected astrocytes (Figure 1D).
Endogenous agmatine production from human arginine decarboxylase ( $\mathrm{hADC}$ )-overexpressed astrocytes

Intracellular levels of agmatine were measured by HPLC (Figure 2). Endogenous agmatine concentration was markedly greater for astrocytes overexpressing hADC compared to that of control astrocytes $(11.28$-fold, $\mathrm{p}<0.001)$. The amount of L-arginine and putrescine (precursor and metabolite of agmatine, respectively) showed similar tendency to that of agmatine. Meanwhile, OGD itself did not have a significant influence on the level of these amines.

Astrocyte-protective effect of human arginine decarboxylase (hADC) transduction against oxygen-glucose deprivation (OGD)

OGD damaged naive astrocytes and the majority of cells had PI-labeled nuclei (Figure 3B). However, astrocytes overexpressing hADC (hADC-astrocytes) were much less damaged by OGD, and the proportion of PI-positive cells were considerably lower (Figure 3D). hADC transduction itself did not have any significant effects on cell viability (Figure 3C), as determined by Hoechst 33258 and PI double nuclear staining.

\section{Neuroprotective effect of human arginine decarboxylase (hADC) transduction on oxygen-glucose deprivation (OGD) and restoration injury}

To mimic the ischemia-reperfusion injury in vivo, cells were restored to normoxic glucose-supplied conditions after 4 hrs of OGD (Figure 4). Cytotoxicity was measured by LDH leakage from the injured cells. Cytotoxicity gradually increased in a time-dependent manner for up to $10 \mathrm{hrs}$ during restoration. Even in hADC-astrocytes, the

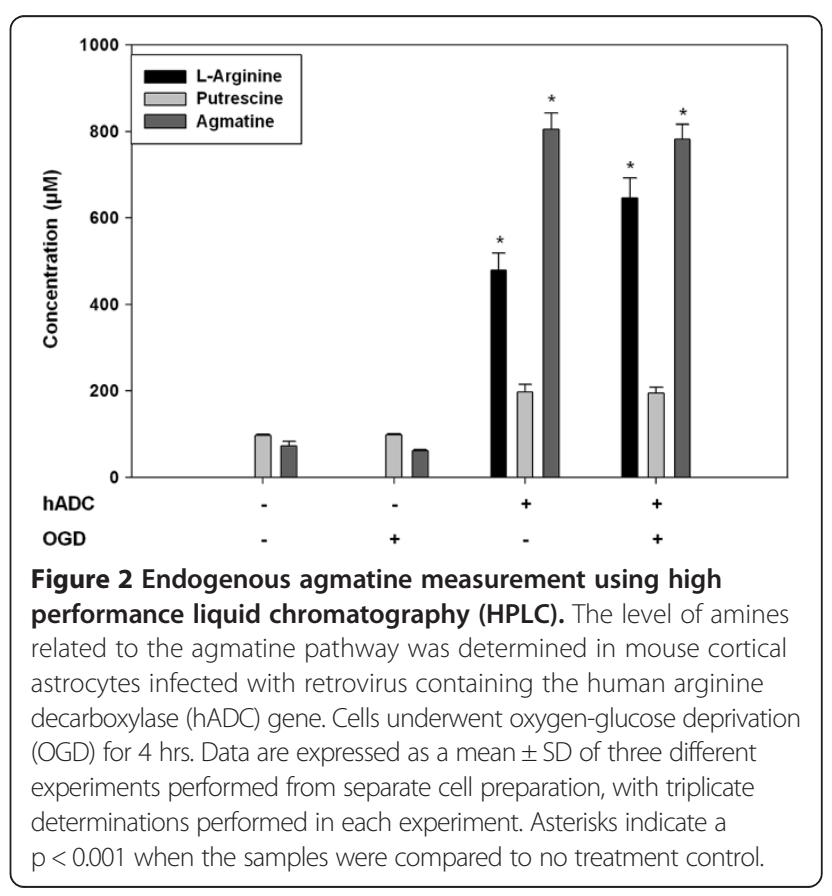



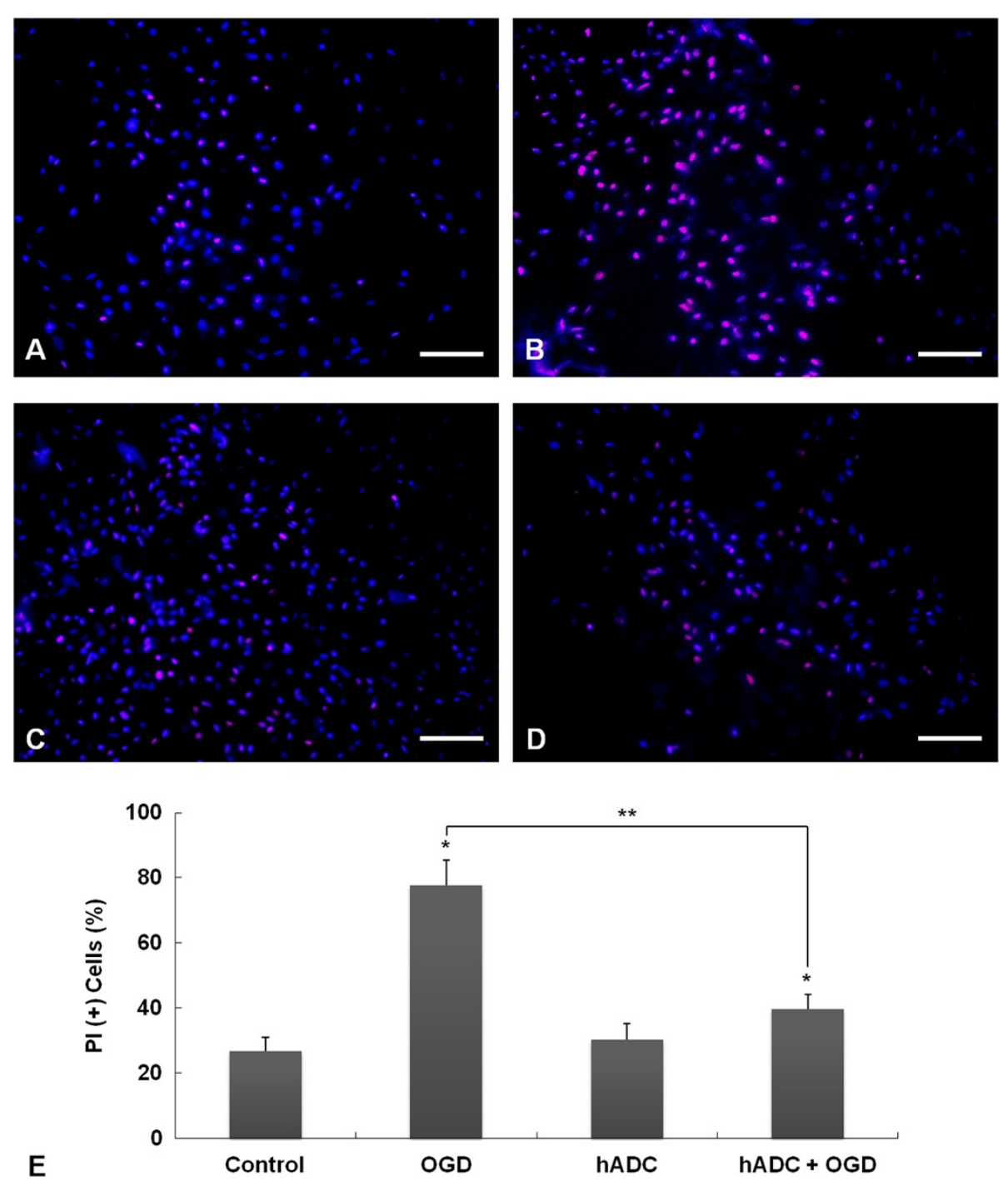

Figure 3 Astrocyte-protective effect of human arginine decarboxylase (hADC) transduction against oxygen-glucose deprivation (OGD). Cytotoxicity was assessed by Hoechst 33258 and propidium iodide (PI) nuclear staining; (A) No treatment control astrocytes, (B) astrocytes after 4 hrs OGD, (C) hADC-overexpressing astrocytes (hADC-astrocytes), (D) hADC-astrocytes after 4 hrs OGD. Scale bars $=100 \mu \mathrm{m}$. (E) Proportion of PI-labeled damaged cells with red fluorescence. Asterisks indicate a $\mathrm{p}<0.05$ when the samples were compared to no treatment control. Double asterisk indicate a $\mathrm{p}<0.05$ that that the two samples were significantly different which was confirmed by a post-hoc analysis.

restoration from OGD caused cytotoxicity in a timedependent-manner; the extent of damage was much less than that in control astrocytes.

Suppression of inducible nitric oxide synthase (iNOS) and matrix metalloproteinases (MMPs) in human arginine decarboxylase (hADC)-overexpressing astrocytes

Expression of iNOS and MMP-2/9 was assessed by RTPCR (Figure 5A) and Western immunoblots (Figure 5B). OGD significantly increased levels of iNOS and MMP-2/9; however, hADC transduction attenuated the OGD effects. Introduction of the hADC gene itself did not change glyceraldehyde 3-phosphate dehydrogenase (GAPDH) and $\beta$-actin levels, which served as internal controls for RT-PCR and Western immunoblots, respectively.

Inhibited expression of inducible nitric oxide synthase (iNOS) and matrix metalloproteinases (MMPs) in human arginine decarboxylase (hADC)-transduced astrocytes Naive astrocytes seldom expressed iNOS and MMP-2/9 (Figure 6A,D,G). After 4 hrs of OGD, control astrocytes exhibited expression of iNOS and MMP-2/9 (Figure 6B, E, H); however, hADC-astrocytes did not show immunoreactivity to either iNOS or MMP-2/9 (Figure 6C, F, I). 


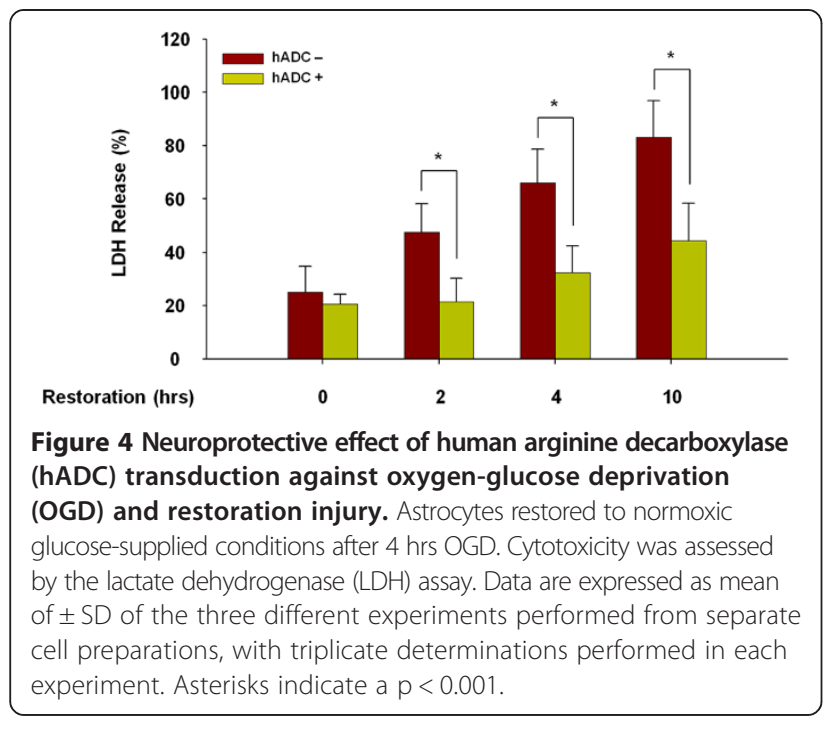

\section{Discussion}

Since Reis and colleagues first discovered agmatine and ADC activity in the mammalian brain [5], agmatine has been widely studied. It is known to have various biological actions through multiple molecular targets, exhibiting affinity not only to $\alpha_{2}$-adrenoceptors and $\mathrm{I}_{1}$ - and $\mathrm{I}_{2}$-imidazoline receptors but also to $\beta$-adrenoceptors and $5-\mathrm{HT}_{3}$ serotonin, nicotinic cholinergic NMDA, $\mathrm{D}_{2}$-dopamine, $\mathrm{k}$ opioid, and adenosine $\mathrm{A}_{1}$ receptors [10-12]. Agmatine also inhibits iNOS/nNOS and monoamine oxidase $[10,14,15]$. As well, agmatine reduces heart rate and blood pressure [10], stimulates insulin and $\beta$-endorphin release, leading to increased cellular glucose uptake [33,34], and accelerates glomerular ultrafiltration [35]. Agmatine protects systemic organs, especially against oxidative stress. Additionally, it shows cardioprotective and renoprotective effects on ischemic insult [36,37], and it directly protects mitochondria from ROS $[38,39]$. In the CNS, agmatine shows neuroprotective effects on various neuronal injuries: reduces the infarct size and edema after cerebral ischemia $[17,18,40]$, attenuates brain damage and reactive gliosis caused by trauma $[41,42]$, and also decreases traumatic/ ischemic spinal cord injuries [43,44]. Agmatine also decreases neuropathic pain and convulsive events [45,46], attenuates opioid dependence and alcohol withdrawal anxiety $[47,48]$, and it improves motor and cognitive functions in Parkinson's and Alzheimer's disease, respectively $[49,50]$. Even in the eyes, agmatine lowers intraocular

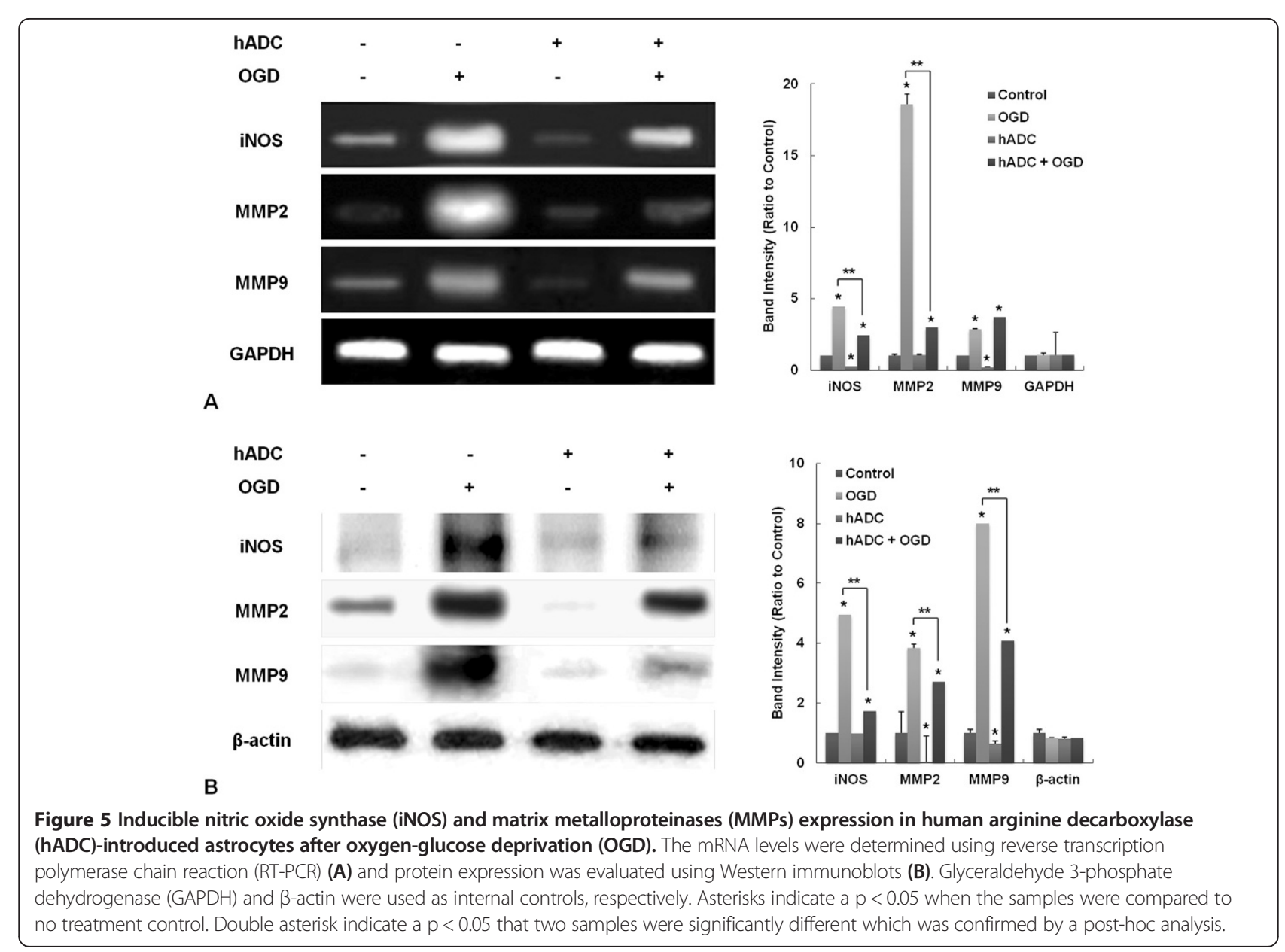



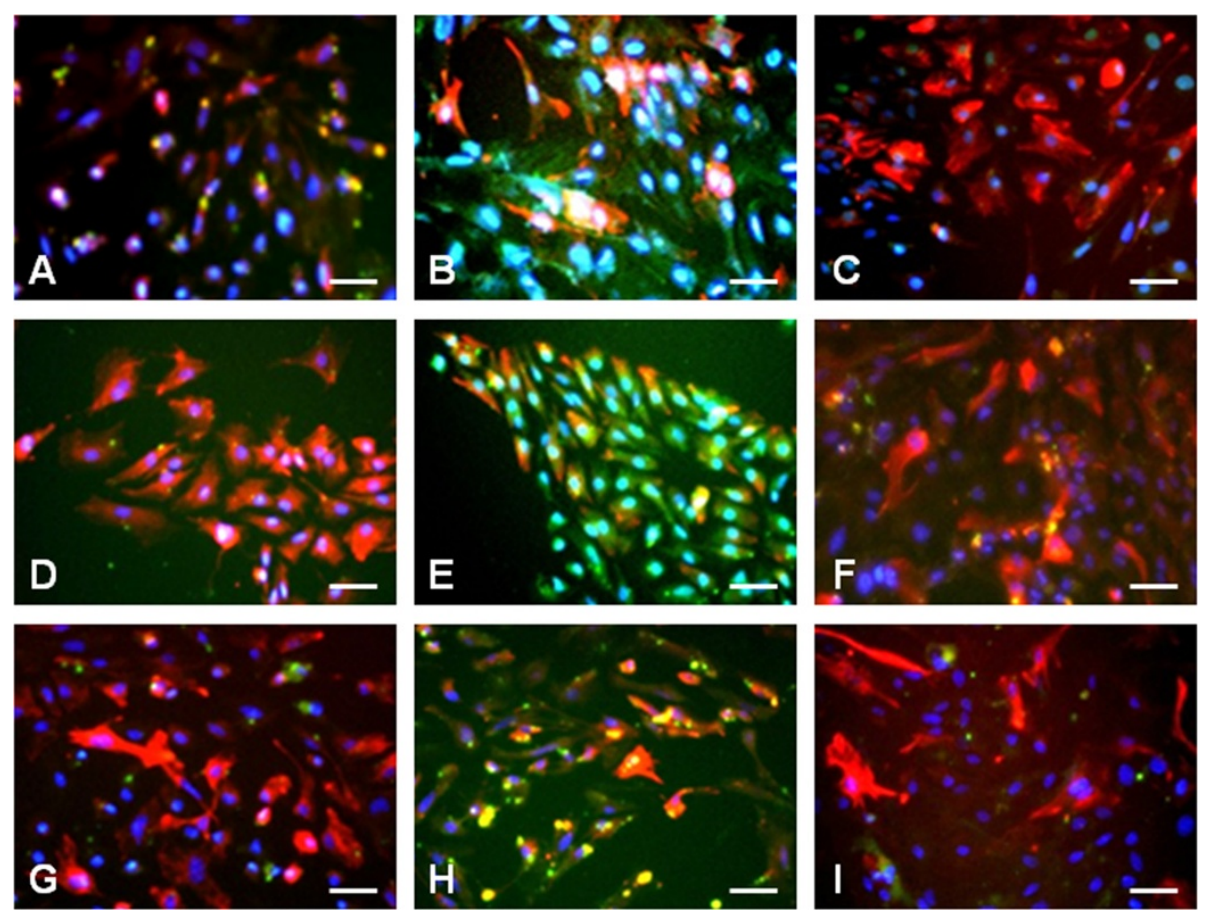

Figure 6 Immunofluorescence staining of human arginine decarboxylase (hADC)-introduced astrocytes after oxygen-glucose deprivation (OGD). (A, D, G) No treatment control astrocytes; (B, E, H) astrocytes after 4 hrs OGD; (C, F, I) hADC-astrocytes after 4 hrs OGD. Cells reacted to inducible nitric oxide synthase (iNOS) (A-C), matrix metalloproteinase (MMP) 2 (D-F), and MMP 9 (G-I) showed green fluorescence. Cells were counter-stained with astrocyte marker glial fibrillary acidic protein (GFAP; red fluorescence) and nuclear marker 4',6-diamidino-2-phenylindole (DAPI; blue fluorescence). Scale bar $=50 \mu \mathrm{m}$.

pressure and protects retinal ganglion cells [51,52]. Taken together, agmatine seems to be a miracle cure rather than a specific drug.

In routine clinical settings, exogenous drug administration may be the most straightforward therapeutic strategy. However, exogenous drug administration is not always the best approach for real patients. Taken orally, agmatine is readily distributed throughout the body $[53,54]$ and can even cross the blood-brain barrier $[55,56]$. Moreover, its reported half-life in the body is about $2 \mathrm{hrs}$ [57]. The various functions of agmatine have pros and cons. In addition to neuronal effects, agmatine also has cardiovascular, endocrinal, renal, gastric, and growth effects [10]. Therefore, taken orally, agmatine may cause unwanted systemic responses. Thus, it is important to focus on the action of the drug at the site of injury and extend its duration of action. In this regard, in the ophthalmologic field, a topical agmatine ophthalmic solution has been formulated to preserve the optic nerves against glaucomatous damage [51]. Agmatine eye drops effectively lower intraocular pressure and protect retinal ganglion cells from chronic ocular pressure injuries. Along the same lines, investigators have attempted to develop a distinctive method for increasing endogenous agmatine production via a recombinant retroviral vector system containing the hADC gene. The hADC gene can be effectively delivered into mouse fibroblast NIH3T3 cells [23], primary mouse cortical neural stem cells [24], and human bone marrow mesenchymal stem cells [25]. Different types of transformed cells synthesize agmatine when they are exposed to hydrogen peroxide, resulting in resistance against oxidative stress. Irrespective of the cell type in an oxidative stressed environment, intracellular agmatine concentration is boosted by about 2 to 5 -fold in hADC-overexpressing cells compared to no treatment control cells, as determined by HPLC [23-25]. While in normal culture conditions, agmatine synthesis is significantly increased in cortical neural stem cells [24] but not fibroblasts or mesenchymal stem cells $[23,25]$. It is not yet clear why the activity of an introduced hADC gene differs according to cell type, especially in non-stressful conditions; nonetheless, it is assumed that agmatine controls the expression of the introduced hADC gene. If normal cells use little agmatine, the transformed cells are presumed not to utilize the introduced ADC without harmful stimuli. However, if normal cells actively use agmatine, the transformed cells are presumed to utilize the introduced ADC. When cells are attacked, all the cell types seem to use the introduced ADC.

In this investigation, we focused on cortical astrocytes, which have recently came to the forefront due to their suspected roles in many CNS injuries, including cerebral 
ischemia [2,3]. Our results showed that intracellular levels of agmatine, as well as its precursor arginine and byproduct putrescine, are definitively increased (about 11 -fold compared to the control, $\mathrm{p}<0.001$ ) in normal and oxidative stressed conditions upon hADC gene transduction, as measured by HPLC. Simultaneously, cell viability was determined by Hoechst /PI double nuclear staining and the LDH assay. hADC-overexpressing cells remained viable and healthy under oxidative stress conditions induced by OGD for 4 hrs. This astrocyte-rescuing property was gradually potentiated as restoration time proceeded for up to 10 hours. In addition, the neuroprotective effect of endogenous agmatine seemed to be related to iNOS intracellular signaling and the activity of MMPs, as assessed by RT-PCR, Western immunoblots, and immunofluorescence. Our present and previous findings are similar to those of other groups in regards to iNOS [15,58-60] and MMPs [61,62], respectively. As MMPs are upregulated by ischemic insult and degrade the basement membrane of brain microvessels [63], their suppression via ADC gene transduction may reduce ischemic injuries. Our retroviral system to deliver the hADC gene to target cells cannot be directly applied to non-dividing cells. Accordingly, another vector system using the Lentivirus is currently under development. It may be directly applied to non-dividing CNS neurons, specifically through in vivo transduction.

\section{Conclusion}

In summary, our findings imply that endogenous agmatine production through ADC gene transduction can protect astrocytes against oxidative stress. The results of this study provide new insights that may lead to novel therapeutic approaches to reduce oxidative stress-related diseases including cerebral ischemia.

\section{Additional file}

Additional file 1: Immunofluorescence staining of primary cultured astrocytes. Cells reacted to anti-glial fibrillary acidic protein (GFAP) (A, red fluorescence), and anti-CD11b (B, green fluorescence) antibodies. Nuclei were counterstained with Hoechst 33258 (C, blue fluorescence). Panel D is a merged image. Scale bar $=200 \mu \mathrm{m}$.

\footnotetext{
Abbreviations

ADC: Arginine decarboxylase; ANOVA: One-way analysis of variance; BSS: Balanced salt solution; CNS: Central nervous system; DAPI: 4',6-diamidino-2phenylindole; DMEM: Dulbecco's modified Eagle's medium; FBS: Fetal bovine serum; GAPDH: Glyceraldehyde 3-phosphate dehydrogenase; GFAP: Glial fibrillary acidic protein; hADC: Human arginine decarboxylase; HPLC: High performance liquid chromatography; iNOS: Inducible nitric oxide synthase; LDH: Lactate dehydrogenase; MEM: Minimum essential medium; MMP: Matrix metalloproteinase; NMDA: N-methyl-D-aspartic acid; nNOS: Neuronal nitric oxide synthase; OGD: Oxygen-glucose deprivation; PCR: Polymerase chain reaction; PI: Propidium iodide; ROS: Reactive oxygen species; RT-PCR: Reverse transcription polymerase chain reaction.
}

\section{Competing interests}

The authors declare that they have no competing interests.

\section{Authors' contributions}

$L J E, H S$, and SMR designed the experiments. HS, SMR, and YK carried out the molecular studies and Lee JE supervised the whole process. HS and SMR wrote the bulk of the manuscript and LWT and PKA revised the manuscript. LJE has given final approval of the version to be published. All authors read approved the final manuscript.

\section{Acknowledgment}

This work was supported by Basic Science Research Program through the National Research Foundation of Korea (NRF) funded by the Ministry of Education, Science and Technology (MEST) (No. 2011-0013288, 20120005440) and by the Brain Korea 21 Project for Medical Science, Yonsei University, Seoul, Republic of Korea.

\section{Author details}

${ }^{1}$ Institute of Vision Research, Department of Ophthalmology, Yonsei University College of Medicine, Seoul, Republic of Korea. ${ }^{2}$ Brain Korea 21 Project for Medical Science, and Brain Research Institute, Department of Anatomy, Yonsei University College of Medicine, 50 Yonsei-ro,

Seodaemun-gu, Seoul 120-752, Republic of Korea.

Received: 26 March 2014 Accepted: 20 August 2014

Published: 26 August 2014

\section{References}

1. Heneka MT, Rodríguez JJ, Verkhratsky A: Neuroglia in neurodegeneration. Brain Res Rev 2010, 63:189-211.

2. Barreto G, White RE, Ouyang Y, Xu L, Giffard RG: Astrocytes: targets for neuroprotection in stroke. Cent Nerv Syst Agents Med Chem 2011, 11:164-173.

3. Nedergaard M, Dirnagl U: Role of glial cells in cerebral ischemia. Glia 2005, 50:281-286.

4. Chen Y, Swanson RA: Astrocytes and brain injury. J Cereb Blood Flow Metab 2003, 23:137-149.

5. Li G, Regunathan S, Barrow CJ, Eshraghi J, Cooper R, Reis DJ: Agmatine: an endogenous clonidine-displacing substance in the brain. Science 1994, 263:966-969.

6. Reis DJ, Regunathan S: Agmatine: an endogenous ligand at imidazoline receptors is a novel neurotransmitter. Ann N Y Acad Sci 1999, 881:65-80.

7. Halaris A, Plietz J: Agmatine: metabolic pathway and spectrum of activity in brain. CNS Drugs 2007, 21:885-900.

8. Reis DJ, Yang XC, Milner TA: Agmatine containing axon terminals in rat hippocampus form synapses on pyramidal cells. Neurosci Lett 1998, 250:185-188.

9. Goracke-Postle CJ, Nguyen HO, Stone LS, Fairbanks CA: Release of tritiated agmatine from spinal synaptosomes. Neuroreport 2006, 17:13-17.

10. Raasch W, Schäfer U, Chun J, Dominiak P: Biological significance of agmatine, an endogenous ligand at imidazoline binding sites. $\mathrm{Br} J$ Pharmacol 2001, 133:755-780.

11. Sugiura T, Kobuchi S, Tsutsui H, Takaoka M, Fujii T, Hayashi K, Matsumura Y: Preventive mechanisms of agmatine against ischemic acute kidney injury in rats. Eur J Pharmacol 2009, 603:108-113.

12. Yang XC, Reis DJ: Agmatine selectively blocks the N-methyl-D-aspartate subclass of glutamate receptor channels in rat hippocampal neurons. J Pharmacol Exp Ther 1999, 288:544-549.

13. Wang G, Gorbatyuk OS, Dayanithi G, Ouyang W, Wang J, Milner TA, Regunathan S, Reis DJ: Evidence for endogenous agmatine in hypothalamo-neurohypophysial tract and its modulation on vasopressin release and Ca2+ channels. Brain Res 2002, 932:25-36.

14. Auguet M, Viossat I, Marin JG, Chabrier PE: Selective inhibition of inducible nitric oxide synthase by agmatine. Jpn J Pharmacol 1995, 69:285-287.

15. Demady DR, Jianmongkol S, Vuletich JL, Bender AT, Osawa Y: Agmatine enhances the NADPH oxidase activity of neuronal NO synthase and leads to oxidative inactivation of the enzyme. Mol Pharmacol 2001, 59:24-29.

16. Uzbay Tl: The pharmacological importance of agmatine in the brain. Neurosci Biobehav Rev 2012, 36:502-519.

17. Kim JH, Yenari MA, Giffard RG, Cho SW, Park KA, Lee JE: Agmatine reduces infarct area in a mouse model of transient focal cerebral ischemia and 
protects cultured neurons from ischemia-like injury. Exp Neurol 2004, 189:122-130.

18. Kim JH, Lee YW, Park KA, Lee WT, Lee JE: Agmatine attenuates brain edema through reducing the expression of aquaporin-1 after cerebral ischemia. J Cereb Blood Flow Metab 2010, 30:943-949.

19. Uranchimeg D, Kim JH, Kim JY, Lee WT, Park KA, Batbaatar G, Tundevrentsen S, Amgalanbaatar D, Lee JE: Recovered changes in the spleen by agmatine treatment after transient cerebral ischemia. Anat Cell Biol 2010, 43:44-53.

20. Wang CC, Chio CC, Chang CH, Kuo JR, Chang CP: Beneficial effect of agmatine on brain apoptosis, astrogliosis, and edema after rat transient cerebral ischemia. BMC Pharmacol 2010, 10:11

21. Lee WT, Hong S, Yoon SH, Kim JH, Park KA, Seong GJ, Lee JE: Neuroprotective effects of agmatine on oxygen-glucose deprived primary-cultured astrocytes and nuclear translocation of nuclear factor-kappa B. Brain Res 2009, 1281:64-70.

22. Ahn SK, Hong S, Park YM, Lee WT, Park KA, Lee JE: Effects of agmatine on hypoxic microglia and activity of nitric oxide synthase. Brain Res 2011, 1373:48-54.

23. Moon SU, Kwon KH, Kim JH, Bokara KK, Park KA, Lee WT, Lee JE: Recombinant hexahistidine arginine decarboxylase (hisADC) induced endogenous agmatine synthesis during stress. Mol Cell Biochem 2010, 345:53-60.

24. Bokara KK, Kwon KH, Nho Y, Lee WT, Park KA, Lee JE: Retroviral expression of arginine decarboxylase attenuates oxidative burden in mouse cortical neural stem cells. Stem Cells Dev 2011, 20:527-537.

25. Seo SK, Yang W, Park YM, Lee WT, Park KA, Lee JE: Overexpression of human arginine decarboxylase rescues human mesenchymal stem cells against $\mathrm{H} 2 \mathrm{O} 2$ toxicity through cell survival protein activation. J Korean Med Sci 2013, 28:366-373.

26. Lee JE, Kim CY, Giaccia AJ, Giffard RG: The E6 and E7 genes of human papilloma virus-type 16 protect primary astrocyte cultures from injury. Brain Res 1998, 795:10-16.

27. Hong S, Lee JE, Kim CY, Seong GJ: Agmatine protects retinal ganglion cells from hypoxia-induced apoptosis in transformed rat retinal ganglion cell line. BMC Neurosci 2007, 8:81

28. Wroblewski F, Ladue JS: Lactic dehydrogenase activity in blood. Proc Soc Exp Biol Med 1955, 90:210-213.

29. Koh JY, Choi DW: Quantitative determination of glutamate mediated cortical neuronal injury in cell culture by lactate dehydrogenase efflux assay. J Neurosci Methods 1987, 20:83-90.

30. Hong S, Kim CY, Lee JE, Seong GJ: Agmatine protects cultured retinal ganglion cells from tumor necrosis factor-alpha-induced apoptosis. Life Sci 2009, 84:28-32.

31. Hong S, lizuka Y, Kim CY, Seong GJ: Isolation of primary mouse retinal ganglion cells using immunopanning-magnetic separation. Mo/ Vis 2012, 18:2922-2930.

32. Bechara Rl, Brown LA, Roman J, Joshi PC, Guidot DM: Transforming growth factor beta 1 expression and activation is increased in the alcoholic rat lung. Am J Respir Crit Care Med 2004, 170:188-194.

33. Sener A, Lebrun P, Blachier F, Malaisse WJ: Stimulus-secretion coupling of arginine-induced insulin release. Insulinotropic action of agmatine. Biochem Pharmacol 1989, 38:327-330.

34. Chang CH, Wu HT, Cheng KC, Lin HJ, Cheng JT: Increase of beta-endorphin secretion by agmatine is induced by activation of imidazoline I(2A) receptors in adrenal gland of rats. Neurosci Lett 2010, 468:297-299.

35. Schwartz D, Peterson OW, Mendonca M, Satriano J, Lortie M, Blantz RC: Agmatine affects glomerular filtration via a nitric oxide synthasedependent mechanism. Am J Physio/ 1997, 272:F597-F601.

36. Greenberg S, George J, Wollman Y, Shapira I, Laniado S, Keren G: The effect of agmatine administration on ischemic-reperfused isolated rat heart. J Cardiovasc Pharmacol Ther 2001, 6:37-45.

37. Sugiura T, Tsutsui H, Takaoka M, Kobuchi S, Hayashi K, Fujii T, Matsumura Y: Protective effect of agmatine on ischemia/reperfusion-induced renal injury in rats. J Cardiovasc Pharmacol 2008, 51:223-230.

38. Arndt MA, Battaglia V, Parisi E, Lortie MJ, Isome M, Baskerville C, Pizzo DP, lentile R, Colombatto S, Toninello A, Satriano J: The arginine metabolite agmatine protects mitochondrial function and confers resistance to cellular apoptosis. Am J Physiol Cell Physiol 2009, 296:C1411-C1419.
39. Battaglia V, Grancara S, Satriano J, Saccoccio S, Agostinelli E, Toninello A: Agmatine prevents the $\mathrm{Ca}(2+)$-dependent induction of permeability transition in rat brain mitochondria. Amino Acids 2010, 38:431-437.

40. Huang YC, Tzeng WS, Wang CC, Cheng BC, Chang YK, Chen HH, Lin PC, Huang TY, Chuang TJ, Lin JW, Chang CP: Neuroprotective effect of agmatine in rats with transient cerebral ischemia using MR imaging and histopathologic evaluation. Magn Reson Imaging. 2013, 31:1174-1181.

41. Sengul G, Takci E, Malcok UA, Akar A, Erdogan F, Kadioglu HH, Aydin IH: A preliminary histopathological study of the effect of agmatine on diffuse brain injury in rats. J Clin Neurosci 2008, 15:1125-1129.

42. Kuo JR, Lo CJ, Chang CP, Lin KC, Lin MT, Chio CC: Agmatine-promoted angiogenesis, neurogenesis, and inhibition of gliosis-reduced traumatic brain injury in rats. J Trauma 2011, 71:E87-E93.

43. Gilad GM, Gilad VH: Accelerated functional recovery and neuroprotection by agmatine after spinal cord ischemia in rats. Neurosci Lett 2000, 296:97-100.

44. Yu CG, Marcillo AE, Fairbanks CA, Wilcox GL, Yezierski RP: Agmatine improves locomotor function and reduces tissue damage following spinal cord injury. Neuroreport 2000, 11:3203-3207.

45. Onal A, Delen Y, Ulker S, Soykan N: Agmatine attenuates neuropathic pain in rats: possible mediation of nitric oxide and noradrenergic activity in the brainstem and cerebellum. Life Sci 2003, 73:413-428.

46. Su RB, Wei XL, Zheng JQ, Liu Y, Lu XQ, Li J: Anticonvulsive effect of agmatine in mice. Pharmacol Biochem Behav 2004, 77:345-349.

47. Regunathan S: Agmatine: biological role and therapeutic potentials in morphine analgesia and dependence. AAPS J 2006, 8:E479-E484.

48. Taksande BG, Kotagale NR, Patel MR, Shelkar GP, Ugale RR, Chopde CT: Agmatine, an endogenous imidazoline receptor ligand modulates ethanol anxiolysis and withdrawal anxiety in rats. Eur J Pharmacol 2010, 637:89-101.

49. Wiesinger $\mathrm{H}$ : Arginine metabolism and the synthesis of nitric oxide in the nervous system. Prog Neurobiol 2001, 64:365-391.

50. Condello S, Calabrò E, Caccamo D, Currò M, Ferlazzo N, Satriano J, Magazù S, Lentile R: Protective effects of agmatine in rotenone-induced damage of human SH-SY5Y neuroblastoma cells: fourier transform infrared spectroscopy analysis in a model of Parkinson's disease. Amino Acids 2012, 42:775-781.

51. Hong S, Kim CY, Lee WS, Shim J, Yeom HY, Seong GJ: Ocular hypotensive effects of topically administered agmatine in a chronic ocular hypertensive rat model. Exp Eye Res 2010, 90:97-103.

52. Hong S, Hara H, Shimazawa M, Hyakkoku K, Kim CY, Seong GJ: Retinal protective effects of topically administered agmatine on ischemic ocular injury caused by transient occlusion of the ophthalmic artery. Braz J Med Biol Res 2012, 45:212-215.

53. Molderings GJ, Heinen A, Menzel S, Lubbecke F, Homann J, Gothert M: Gastrointestinal uptake of agmatine: distribution in tissues and organs and pathophysiologic relevance. Ann N Y Acad Sci 2003, 1009:44-51.

54. Haenisch B, von Kugelgen I, Bonisch H, Gothert M, Sauerbruch T, Schepke M, Marklein G, Hofling K, Schroder D, Molderings GJ: Regulatory mechanisms underlying agmatine homeostasis in humans. Am J Physiol Gastrointest Liver Physiol 2008, 295:G1104-G1110.

55. Nguyen $\mathrm{HO}$, Goracke-Postle CJ, Kaminski LL, Overland AC, Morgan AD, Fairbanks CA: Neuropharmacokinetic and dynamic studies of agmatine (decarboxylated arginine). Ann N Y Acad Sci 2003, 1009:82-105.

56. Piletz JE, May PJ, Wang G, Zhu H: Agmatine crosses the blood-brain barrier. Ann N Y Acad Sci 2003, 1009:64-74.

57. Huisman H, Wynveen P, Nichkova M, Kellermann G: Novel ELISAs for screening of the biogenic amines GABA, glycine, beta-phenylethylamine, agmatine, and taurine using one derivatization procedure of whole urine samples. Anal Chem 2010, 82:6526-6533.

58. Satriano J, Schwartz D, Ishizuka S, Lortie MJ, Thomson SC, Gabbai F, Kelly CJ, Blantz RC: Suppression of inducible nitric oxide generation by agmatine aldehyde: beneficial effects in sepsis. J Cell Physiol 2001, 188:313-320.

59. Regunathan S, Piletz JE: Regulation of inducible nitric oxide synthase and agmatine synthesis in macrophages and astrocytes. Ann N Y Acad Sci 2003, 1009:20-29.

60. Satriano J: Arginine pathways and the inflammatory response: interregulation of nitric oxide and polyamines: review article. Amino Acids 2004, 26:321-329.

61. Yang MZ, Mun CH, Choi YJ, Baik JH, Park KA, Lee WT, Lee JE: Agmatine inhibits matrix metalloproteinase- 9 via endothelial nitric oxide synthase in cerebral endothelial cells. Neurol Res 2007, 29:749-754. 
62. Jung HJ, Yang MZ, Kwon KH, Yenari MA, Choi YJ, Lee WT, Park KA, Lee JE: Endogenous agmatine inhibits cerebral vascular matrix metalloproteinases expression by regulating activating transcription factor 3 and endothelial nitric oxide synthesis. Curr Neurovasc Res 2010, 7:201-212.

63. Heo JH, Lucero J, Abumiya T, Koziol JA, Copeland BR, del Zoppo GJ: Matrix metalloproteinases increase very early during experimental focal cerebral ischemia. J Cereb Blood Flow Metab 1999, 19:624-633.

doi:10.1186/1471-2202-15-99

Cite this article as: Hong et al:: Retroviral expression of human arginine decarboxylase reduces oxidative stress injury in mouse cortical astrocytes. BMC Neuroscience 2014 15:99.

\section{Submit your next manuscript to BioMed Central and take full advantage of:}

- Convenient online submission

- Thorough peer review

- No space constraints or color figure charges

- Immediate publication on acceptance

- Inclusion in PubMed, CAS, Scopus and Google Scholar

- Research which is freely available for redistribution 